\title{
EFEITOS E LIMITES DE UM PROGRAMA DE HABILIDADES SOCIAIS EDUCATIVAS PARA PAIS DE CRIANÇAS COM TDAH
}

\author{
EFFECTS AND LIMITS OF AN \\ EDUCATION SOCIAL SKILLS \\ PROGRAM FOR PARENTS \\ OF CHILDREN WITH ADHD
}

\author{
FERREIRA, Mariana Carolina Batista ${ }^{7}$ \\ AYALLA, Keyla Oliveira ${ }^{2}$ \\ de OLIVEIRA, Mariana Matheus ${ }^{3}$ \\ ROCHA, MargaretteMatesco ${ }^{4}$
}

\section{RESUMO}

Este artigo apresenta um programa de treinamento em Habilidades Sociais Educativas (HSE) desenvolvido com pais de crianças com diagnóstico de TDAH e estudantes de escolas públicas, bem como seus efeitos. O programa foi conduzido entre os anos de 2010 e 2013, totalizando a participação de 13 pais. O objetivo foi oferecer um espaço para debate e troca de experiências, visando capacitá-los para lidar com demandas interpessoais cotidianas e estabelecerem estratégias que favoreçam o desenvolvimento social e acadêmico de seus filhos. Os dados demonstraram mudanças positivas nas HSE dos pais após a intervenção. Da mesma forma, a maioria das crianças foram avaliadas positivamente pelos pais e professores, alcançando os objetivos traçados. Uma dificuldade encontrada foi a baixa adesão dos pais, inclusive quanto à permanência no programa, indicando necessidade de aprimoramento do programa visando garantir maior adesão, resultando em uma reavaliação quanto ao seu formato e possível adaptação para professores.

Palavras-chave: Treinamento de pais. Habilidades Sociais Educativas. TDAH.

\section{ABSTRACT}

This paper presents a training program in Social Educational Abilities developed with parents of children with a diagnosis of ADHD who study in public schools, as well as its effects. The program was developed between 2010 and 2013, totaling 13 participating parents. The goal was to offer a space for debate and exchange of experiences, seeking to make them better able to deal with the interpersonal daily demands and establish strategies which favor the social and academic development of their children. The data showed positive changes in the parents' Social Educational Abilities after the intervention. Likewise, most children were evaluated positively by the parents and teachers, reaching the aimed goals. One of the

\footnotetext{
1 Aluna do curso de Psicologia da Universidade Estadual de Londrina (UEL), Brasil. E-mail: maribatistaferreira@gmail.com

2 Aluna do curso de Psicologia da Universidade Estadual de Londrina (UEL), Brasil. E-mail: keylla_ayalla@hotmail.com

3 Aluna do curso de Psicologia da Universidade Estadual de Londrina (UEL), Brasil. E-mail: mari.mat@hotmail.com

4 Professora da Universidade Estadual de Londrina (UEL), Brasil. Doutorado em Educação Especial pela Universidade Federal de

São Carlos (UFSCAR), Brasil. E-mail: margarette@uel.br
} 
difficulties found was parents' low adhesion to the project, including issues related to their permanence in the program, indicating the need to upgrade the program seeking to guarantee greater support, resulting in a reevaluation in relation to its format and a possible adaptation for teachers.

Keywords: Parents training. Educative social skills. ADHD.

\section{Introdução}

OTranstorno de Déficit de Atenção e Hiperatividade (TDAH) é caracterizado pelos comportamentos de desatenção, hiperatividade e impulsividade,atingindo cerca de 3 a $6 \%$ das crianças e adolescentes em idade escolar. Segundo o DSM-IV-TR (2000), os sintomas podem apresentar três diferentes tipos de predomínios, incluindo o de desatenção, de hiperatividade-impulsividade ou apresentação combinada desses sintomas. Para o diagnóstico, dentre outros, é importante identificar comprometimentos em pelo menos dois ambientes diferentes, por exemplo, casa e escola, e no desempenho da vida acadêmica, social, profissional, etc. No que concerne a sua etiologia, o TDAH é entendido como um distúrbio neurobiológico, sendo que condiçóes hereditárias e ambientais são destacadas como possíveis fatores etiológicos (ROESER; ECCLES, 2000; ROHDE, et al., 2004).

Em comparação com as crianças sem o transtorno, estudantes com TDAH geralmente apresentam maior risco de fracasso escolar, maior incidência de suspensóes, expulsóes e reprovaçóes escolares, menor grau de escolaridade em relaçáo ao seu potencial e têm menor probabilidade de completar seus estudos (DuPAUL; WHITE, 2006; BARKLEY; PFIFFNER, 2002; ROHDE et al., 1999). Além disso, é estimado que 50 a 60\% das crianças com TDAH experienciam alguma forma de rejeição social pelos colegas. Quando são socialmente rejeitadas na infância, apresentam taxas mais altas de fracasso e desistência escolar, infraçóes delinquentes, sentimentos de solidão e baixa autoestima (BARKLEY, 1998).

No Brasil, o estudo de Freitas (2013) mostrou que de fato crianças com TDAH apresentam menor frequência de habilidades sociais quando comparadas a outras crianças consideradas população-alvo da educação especial (autismo, deficiência auditiva, deficiência intelectual leve, deficiência intelectual moderada, deficiência visual, desvio fonológico, dificuldades de aprendizagem, dotação e talento, problemas de comportamento internalizantes e externalizantes).

Considerando os efeitos do TDAH sobre a vida acadêmica e social dessas crianças, de acordo com os atuais critérios para definição da população alvo da educação especial, descritos na Política Nacional de Diretrizes da Educação Especial (BRASIL, 2008), o TDAH passou a ser entendido como um transtorno funcional específico, em que a educação especial deve atuar de forma articulada com o ensino comum, orientando para o atendimento às necessidades educacionais especiais desses alunos. Além disso, a educação especial deve direcionar suas ações, dentre inúmeras outras, na organização de redes de apoio para a inclusão, que inclui de forma preponderante a família dessas crianças.

Isso não significa reduzir o papel dos professores nessa tarefa nem imputar à família a responsabilidade por esse processo. Entende-se que a família,componente ativo, contribuinte e essencial à educação dos filhos, divide responsabilidades com a escola para enfrentar os desafios da escolarização impostos à criança com TDAH (ROCHA; DEL PRETTE, 2010).

Além disso, para Condemarín et al. (2006), as intervençóes no ambiente familiar e escolar justificam-se pelo fato do quadro da criança com TDAH estar suscetível à evolução para formas mais positivas ou então piorar, a depender das condiçóes que lhe são oferecidas. Assim, a qualidade dos contextos escolar e familiar pode constituir fator determinante para a forma como a criança vive suas dificuldades e os mecanismos que utiliza para superá-las. 
A análise das interaçóes familiares aponta que o comportamento inadequado da criança com TDAH afeta de forma considerável sua interação com os pais, pois seus comportamentos, geralmente, são entendidos como infraçóes resultando em uma frequência elevada de comportamentos punitivos por parte dos pais e outros familiares (BARKLEY,1998).

Ainda nesse sentido, o estudo de Bellé et al (2009, p. 322) demonstrou que mães de crianças com TDAH apresentam elevada sobrecarga emocional, pois, geralmente, encontram-se em um estado de cansaço e tensão acentuados devido, principalmente, aos comportamentos dos filhos, preocupaçáo com o seu futuro e casos de ressentimento na família. A sobrecarga emocional é decorrente, segundo os autores, de um maior investimento e maior assistência que essas crianças demandam, além das frequentes queixas em relação aos seus comportamentos e à responsabilização da mãe pela falta de controle sobre o mesmo.

Assim, pais precisam ser instrumentalizados em estratégias para aumentar a frequência de comportamentos acadêmicos, sociais e afetivos de seus filhos de modo a promover o pleno desenvolvimento deles e diminuir os conflitos familiares, a sobrecarga emocional e o estresse característicos dessas famílias. Quando os pais são bem-sucedidos, essas mudanças acabam funcionando também para manter esses comportamentos parentais efetivos.

Dentre as habilidades parentais, Del Prette e Del Prette (2008) defendem que, como educadores, os pais devem apresentar um conjunto de habilidades sociais educativas (HSE) visando a promover o desenvolvimento e a aprendizagem dos filhos. Essas habilidades representam um conjunto de açóes potencialmente eficazes para estabelecer condiçóes no ambiente familiar visandoa modificação do comportamento da criança. Essas e outras açóes estáo organizadas por Del Prette e Del Prette (2008) em quatro conjuntos mais gerais: 1) Estabelecer contextos interativos potencialmente educativos; 2) Transmitir ou expor conteúdos; 3) Estabelecer limites e disciplina; 4) Monitorar positivamente.

Cabe ressaltar que, ao abordar o campo das Habilidades Sociais (HS), se faz relevante elucidar que o termo faz referência a uma classe de comportamentos que, como quaisquer outros, se constroem e se mantêm a partir da relaçáo entre o indivíduo e seu ambiente, conforme afirma Lopes (2013). Desse modo, o desenvolvimento de uma "habilidade social" reflete uma história de aprendizado de comportamentos valorizados socialmente e que sáo mantidos no repertório comportamental pelas consequências produzidas no contexto atual.

O entendimento que as habilidades sociais são comportamentos que podem ser aprendidos, viabiliza as propostas de intervenção para alterar os padróes comportamentais considerados socialmente indesejáveis. A manutenção desse padrão comportamental pode trazer dificuldade para o indivíduo em sua convivência com os demais, contribuindo para manter condiçốes aversivas na vida do mesmo, tais como a privação de relacionamentos afetivos variados e a redução da probabilidade de resoluçáo de conflitos (LOPES, 2013; DEL PRETTE; DEL PRETTE, 2005; 2010).

Seguindo esse enfoque, Rocha $(2009$; 2013) desenvolveu um programa para pais de crianças com TDAH designado para avaliar os efeitos diretos do programa sobre os comportamentos das máes e os indiretos sobre os comportamentos dos filhos. Diferentemente de outros programas destinados a pais dessas crianças, o programa desenvolvido tomou como premissa básica que as modificaçóes nos comportamentos dos 
pais podem alterar o ambiente familiar, favorecendo a modificaçáo do comportamento da criança e, consequentemente, mantendo esses comportamentos parentais. Posteriormente, esse programa foi adaptado e replicado a outros três grupos de pais. Os resultados desses atendimentos indicaram efeitos positivos sobre as habilidades sociais cotidianas e educativas dos pais e dos filhos, principalmente nos comportamentos sociais que foram alvos da intervenção.

Assim, essas pesquisas ofereceram subsídios para a disseminação desse programa para a comunidade, pois como sugere Murta (2011), ganhos mais expressivos para os usuários podem advir da implementaçáo de programas com eficácia e efetividade já constatadas, em vez de programas baseados no senso comum ou em critérios estritamente políticos.

A partir das evidências acima, o projeto de extensão "Grupo de Habilidades Sociais Educativas para pais de crianças com TDAH" foi elaborado visando oferecer aos pais de crianças com TDAH um espaço para troca de experiências e para refletir e discutir sobre o transtorno e as implicaçôes para as crianças e suas famílias, bem como para capacitá-los a atuar de forma ativa e efetiva no desenvolvimento das habilidades sociais e acadêmicas de seus filhos com TDAH. Adicionalmente, o projeto visou capacitar os alunos graduandos para atuaçáo prática de atendimento psicológico e para reflexão do papel do psicólogo na criaçáo de uma cultura de educação inclusiva.

\section{Método}

O projeto de extensáo "Grupo de Habilidades Sociais Educativas para pais de crianças com TDAH" foi conduzido por estudantes do curso de Psicologia, que atuaram diretamente com os pais de crianças de escolas públicas que receberam diagnóstico de TDAH. O objetivo foi oferecer a esses pais um espaço para debate e troca de experiências, expansão de seus conhecimentos sobre o transtorno, bem como capacitá-los para: (1) lidar com demandas interpessoais cotidianas impostas a eles e (2) estabelecer estratégias que favoreçam o desenvolvimento social e acadêmico de seus filhos.

O programa foi ofertado em anos diferentes (2010 a 2013) atendendo quatro grupos de pais. O grupo denominado "G1" foi conduzido no ano de 2010, o denominado "G2" no ano de 2011, "G3" no ano de 2012 e "G4" no ano de 2013. As sessōes foram conduzidas, inicialmente, na clínica-escola de uma universidade pública de uma cidade do Norte do Paraná (G1) e, posteriormente, em duas escolas públicas da mesma cidade. A oferta dos atendimentos nas escolas visou a integração do projeto na comunidade e facilitar o deslocamento dos pais que, geralmente, residem próximos à escola onde seus filhos estudam. Considerando os quatro grupos, houve a participação de treze pais, sendo 04 no G1 (2010), 04 no G2 (2011), 03 no G3 (2012) e 02 no G4 (2013).Desse total, 3 (três) eram pais e 10 (dez) eram mães. As crianças tinham entre 7 e 12 anos, com diagnóstico de TDAH e faziam uso contínuo do medicamento Ritalina ${ }^{\circledR}$. Os pais tinham entre 31 e 59 anos, com nível de escolaridade variando entre ensino fundamental incompleto e ensinomédio completo, com prevalência de ensino fundamental completo.

Para avaliar os efeitos do programa no contexto escolar, os professores de matemática ou de português participaram como informantes no início e no final dos atendimentos, respondendo o Inventário de Sistema de Avaliação de Habilidades Sociais - SSRS-BR 
(Gresham\& Elliott, 1990), versão para professores, que permite avaliar o desempenho social e acadêmico das crianças no contexto escolar.

Com relação ao programa propriamente dito, foi divido em cinco etapas conduzidas ao longo de quatorze encontros, sendo um por semana, com duraçáo de aproximadamente uma hora e trinta minutos cada. Os encontros foram distribuídos em: a) duas sessōes (iniciais) para a apresentação da proposta do programa e avaliação pré-intervenção; b) dez sessóes para desenvolvimento das HSE selecionadas e c) duas sessóes para avaliação pós-intervenção e encaminhamentos. A Tabela 1 apresenta a estrutura geral do programa.

\section{Tabela 1 - Estrutura Geral do Programa}

\begin{tabular}{l|l}
\hline Sessão & Atividades/Temas \\
\hline $1^{\mathrm{a}}$ & Apresentação dos objetivos e procedimentos do programa; \\
\hline $2^{\mathrm{a}}$ & $\begin{array}{l}\text { Aplicação do Inventário de Habilidades Sociais - IHS-Del-Prette (Del Prette\& Del Prette, 2001) e do Sistema de } \\
\text { Avaliação de Habilidades Sociais - SSRS-BR (Gresham\& Elliott, 1990) - versão pais; }\end{array}$ \\
\hline $3^{\mathrm{a}}$ & TDAH: Aspectos gerais; \\
\hline $4^{\mathrm{a}}$ & Princípios de Aprendizagem; \\
\hline $5^{\mathrm{a}}$ & Elogio e Feedback; \\
\hline $6^{\mathrm{a}}$ & Solicitando Mudança de Comportamento; \\
\hline $7^{\mathrm{a}}$ & Estabelecendo Regras e Limites; \\
\hline $8^{\mathrm{a}}$ & Empatia; \\
\hline $9^{\mathrm{a}}$ & Estabelecer contextos potencialmente educativos; \\
\hline $10^{\mathrm{a}}$ & Assertividade; \\
\hline $11^{\mathrm{a}}$ & Lidando com críticas; \\
\hline $12^{\mathrm{a}}$ & Auxiliando o filho na tarefa de casa; \\
\hline $13^{\mathrm{a}}$ & Aplicação dos inventários descritos na 2a sessão; \\
\hline $14^{\mathrm{a}}$ & Encaminhamentos. \\
\hline
\end{tabular}

Todas as sessóes destinadas ao treino das habilidades sociais educativas e cotidianas $\left(3^{a}\right.$ a $12^{a}$ ) seguiam a seguinte estrutura: a) Apresentação e discussão da tarefa de casa. Foram debatidos pontos que facilitaram ou dificultaram sua execução e b) Aplicação dos procedimentos de intervençáo visando à apresentação e modelagem das habilidades, que envolvia: a exposição e discussão da habilidade e utilização de estratégias (vivências, instrução verbal, modelação, modelagem e ensaio comportamental) para ensinar/treinar a habilidade. No decorrer das sessóes, as terapeutas procuravam encorajar a autoexposiçáo, ensinar os participantes a procederem análise funcional das situaçóes relatadas e fornecer reforçamento e feedback positivo.

Por fim, os dados obtidos por meio dos inventários foram aferidos conforme as especificaçôes dos respectivos manuais. Com relação às HSE, as mesmas foram avaliadas por meio de entrevistas (antes e após a intervenção), além de observaçôes no decorrer das sessóes.

Foram consideradas HSE somente aquelas habilidades cujos efeitos produziam ou apresentavam probabilidade de gerar mudanças no repertório comportamental do educando, seguindo o critério de funcionalidade sugerido por Del Prette e Del Prette (2008). Foram selecionadas seis HSE para análise, são elas: a) Aproveitar situaçôes do diaa-dia para ensinar sobre habilidades sociais (uma notícia, um comentário, uma cena); b) Negociar regras; c) Mediar interaçôes (incentivar o filho a conversar com outras pessoas e organizar reuniōes em casa); d) Solicitar informaçóes sobre o desempenho adequado do filho na escola; e) Falar/justificar comportamentos desejáveis; f) Falar/justificar comportamentos indesejáveis. 


\section{Resultados}

A avaliaçáo dos pais sobre as Habilidades Sociais (HS), Problemas de Comportamento das crianças, indicam os efeitos indiretos do programa, visto que as crianças náo participaram diretamente da intervenção.

O Gráfico 1 mostra o Escore Geral das HS das crianças, segundo a avaliação dos pais, obtido a partir o Sistema de Avaliação de Habilidades Sociais (SSRS-BR) nas fases pré e pós-intervenção.

\section{Gráfico 1: Escore Geral das HS das crianças na avaliaçáo dos pais}

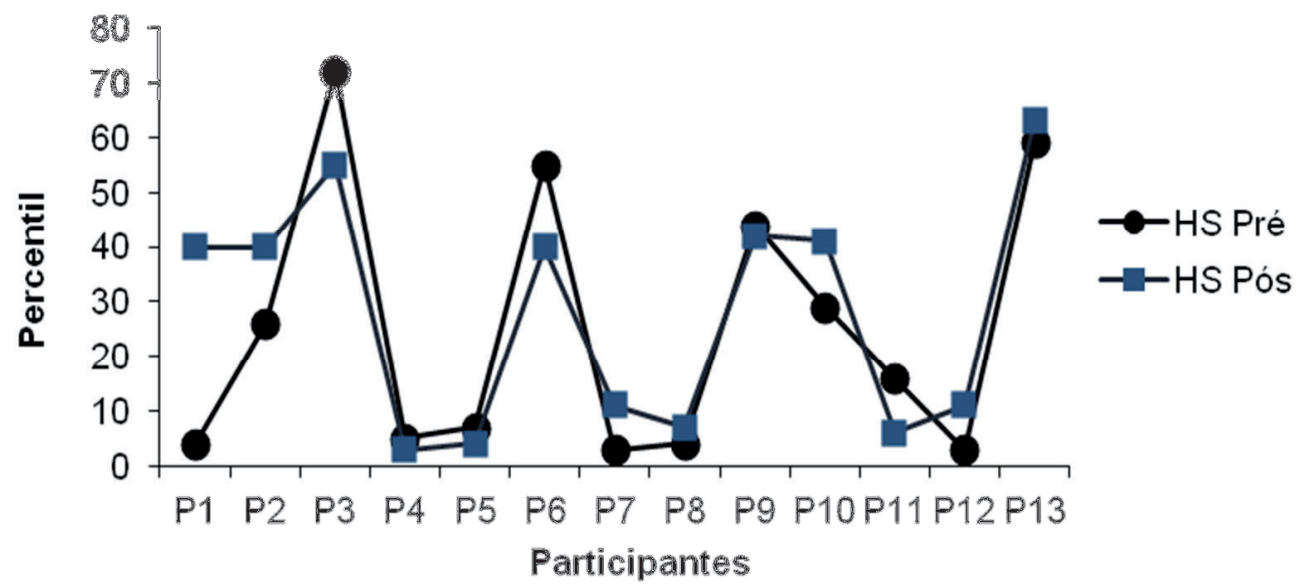

Os resultados referentes ao Escore Geral de P1, P2, P7, P8, P10, P12 e P13, na avaliaçáo pós-intervençáo, indicaram que houve aumento no escore desses participantes, sugerindo efeitos do programa para promoçáo de comportamentos considerados socialmente habilidosos.

Quanto aos fatores de Habilidades Sociais, 11 participantes (P1, P2, P3, P5, P6, P7, P8, P9, P10, P12 e P13) desenvolveram e/ou aprimoraram seus repertórios em pelo menos um dos fatores avaliados. O participante P1 avaliou positivamente seu filho em todos os fatores medidos, sugerindo melhora no comportamento da criança. Em sequência, o resultado do participante P12 sugeriu que o desempenho de seu filho melhorou em cinco das seis habilidades avaliadas, enquanto na avaliação de P7, seu filho apresentou mudança positiva em quatro fatores avaliados. Já na avaliação de P2, P8 e $\mathrm{P} 10$, seus filhos apresentaram mudança positiva em três fatores.

Dentre os fatores avaliados, observou-se ganhos mais acentuados no Fator 5 Autocontrole e Civilidade (7 participantes), seguido dos fatores F1 - Cooperaçáo, F3 - Iniciativa/desenvoltura social e F4- Asserção (6 participantes). As mudanças menos evidentes foram observadas nos fatores F6 - Autocontrole passivo (5 participantes) e F2 Amabilidade (3 participantes).

Os dados referentes ao Escore Geral dos Comportamentos Problemáticos (CP) avaliados pelos pais, nas fases pré e pós-intervenção, estão apresentados no Gráfico 2.

Os dados apresentados no Gráfico 2 apontam reduçáo de frequência no Escore Geral, na avaliação de pós-intervençáo, para os participantes P1, P4, P7, P10, P11 e P12, indicando melhoras no comportamento problemático apresentados pelas crianças.

Em relação aos fatores, de modo geral, oito participantes apresentaram ganhos no F3 (Comportamento internalizante) e seis participantes nos fatores: F1 (Hiperatividade) 
e F2 (Comportamento externalizante). Observou-se que apenas o participante P6 não apresentou redução em nenhum dos fatores avaliados após a intervenção. Por outro lado, P1, P8 e P10 apresentaram redução nos três fatores medidos. Os resultados de P2 e P7 mostraram melhoras em dois dos três fatores avaliados, com maior impacto sobre o F1 (Hiperatividade) para os dois participantes. Os demais participantes (P3, P4, P5, P9, P11, P12 e P13) obtiveram ganhos com o programa em um dos fatores avaliados, com predominância de ganhos no F3 - Comportamentos Internalizantes (4 participantes), seguido de F2 - Comportamentos Externalizantes (2 participantes).

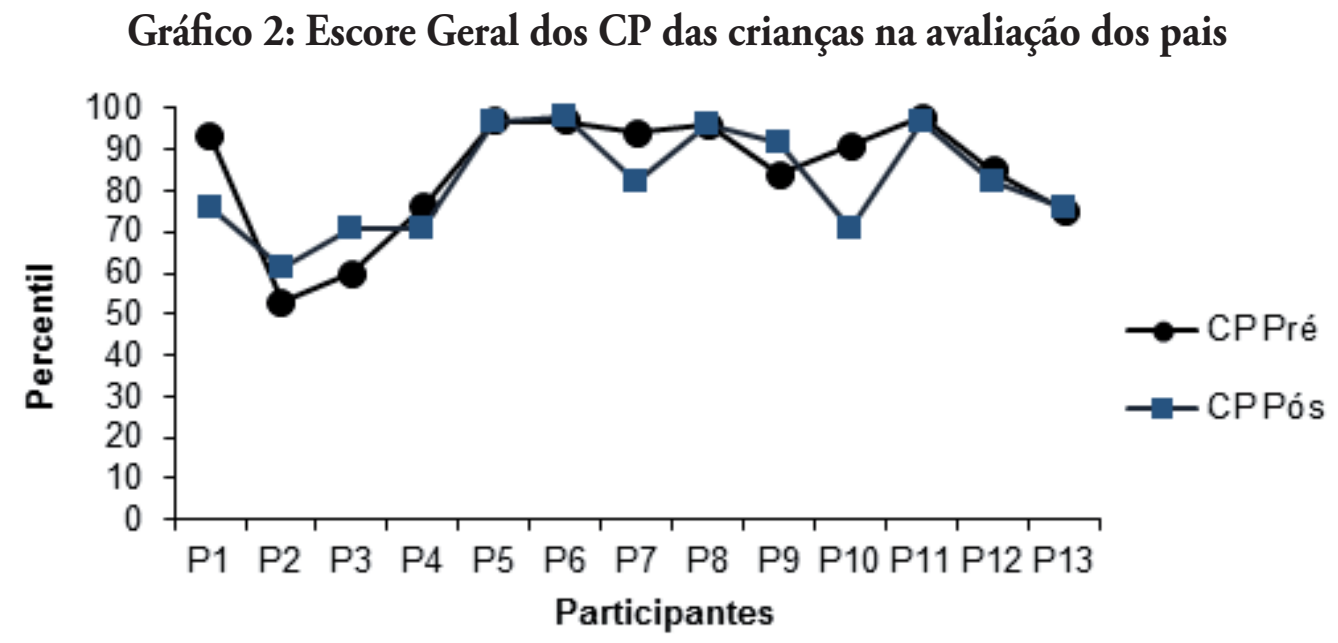

O Gráfico 3 exibe a avaliaçáo dos professores acerca da Competência Acadêmica (CA) das crianças antes e após a intervenção. Cabe destacar que os professores dos filhos dos participantes P3 e P4 não participaram da avaliação.

\section{Gráfico 3: Percentil dos CA das crianças na avaliação dos professores}

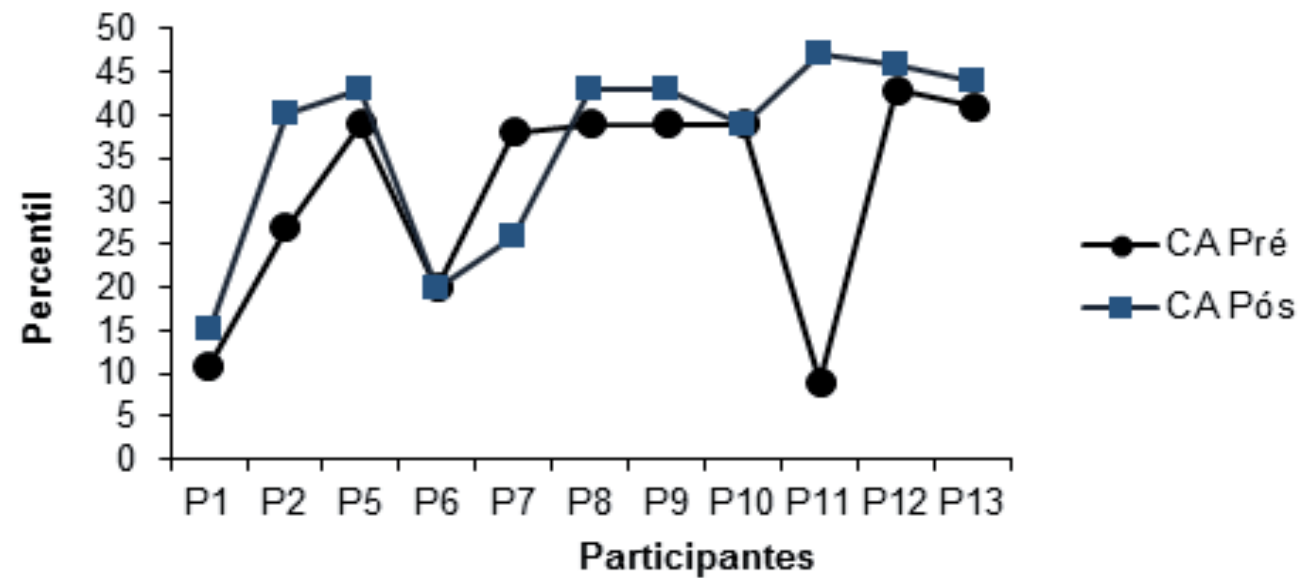

Os escores obtidos na avaliação dos professores indicaram que o desempenho acadêmico dos participantes P1, P2, P5, P8, P9, P11, P12 P13 melhorou na fase pósintervenção, indicando que as crianças obtiveram melhora em seu desempenho escolar após o treinamento dos pais. Por outro lado, os escores referentes ao desempenho de P6 e P10 parecem indicar certa estagnação entre uma fase e outra. Cabe ressaltar ainda que a avaliaçáo do professor colaborador P6 e do professor P7 diz respeito a uma mesma criança, uma vez que seus pais participavam do programa. 
O Gráfico 4 demonstra os Escores Globais obtidos por meio do IHS - Del - Prette (2001), segundo a autoavaliação dos pais, nas fases pré e pós-intervenção. Cabe destacar que, nessa avaliação, o participante $\mathrm{P} 3$ não pode comparecer.

\section{Gráfico 4: Percentil das HS Cotidianas dos pais na avaliaçáo com o IHS-Del -Prette}

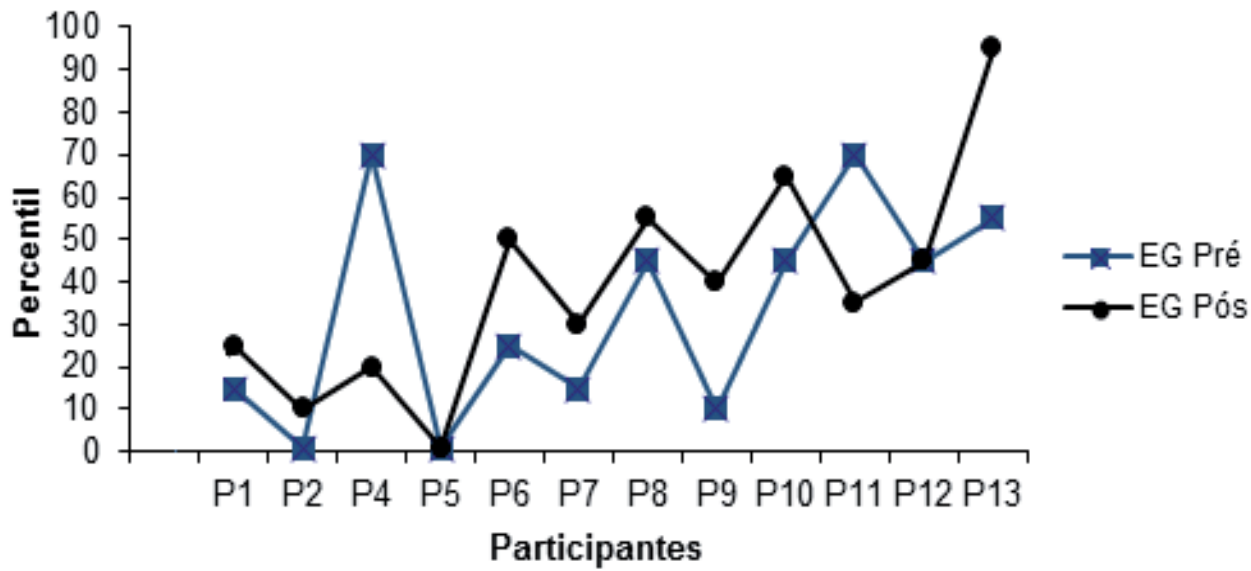

Em relação ao Escore Geral que contempla todas as habilidades avaliadas pelo instrumento, notou-se que os escores de oito dos doze participantes aumentaram após a intervenção, sugerindo benefícios com o programa mesmo nas classes de habilidades que não foram alvo direto de treinamento.

Os participantes P1, P7 e P9 alcançaram na fase pós-intervenção escores superiores a $25 \%$ (repertório abaixo da média, porém frequente), indicando desenvolvimento positivo comparado à fase pré-intervençáa (inferior a $25 \%$, pouco frequente), enquanto P6, P8, P10 e P13 obtiveram escores igual ou superior a 50\% (igual ou acima da média). P1, apesar de apresentar escore que sugeriu ganhos com o programa, o mesmo náo foi suficiente para alterar sua posiçáo (inferior a 25\%). Os participantes P4 e P11 apresentaram reduçáo em seus escores após a intervenção, já os escores apresentados por P5 e P12 na fase pósintervenção não sofreram alteração comparados à fase pré-intervenção.

A Tabela 2 apresenta os dados referentes aos Escores obtidos nos Fatores de Enfrentamento com Riscos (F1) e Expressão de Afeto Positivo (F2), diretamente treinados no programa ao longo da intervenção.

No Fator 1, "Habilidades de enfrentamento com risco", foram trabalhadas as habilidades para lidar com críticas e assertividade. Notou-se que oito participantes apresentaram escore superior a 50\%, sendo que três deles (P1, P7 e P10), alcançaram escores superiores a $75 \%$ (bastante elaborado), indicando o desenvolvimento de repertório compatível com um desempenho de respostas consideradas satisfatórias e adequadas pelo ambiente social, aumentando a probabilidade de relaçóes menos conflituosas.

Quanto ao Fator 2, "Habilidades de autoafirmação na expressão de afeto positivo", em que foram trabalhadas as habilidades de Elogiar e Dar Feedback, nove participantes alcançaram mudança positiva. Os participantes $\mathrm{P} 2, \mathrm{P} 4, \mathrm{P} 9$ e P10 obtiveram escores igual ou superior a $75 \%$, sugerindo o desenvolvimento de um repertório bastante elaborado, enquanto $\mathrm{P} 1$ apresentou escore superior a 50\% (acima da média). Os participantes P6, P8, P12 e P13, apesar de terem se beneficiado com o programa, não alcançaram escores igual ou superior a $50 \%$ (média), indicando ainda a necessidade de treinamento. 


\section{Tabela 2 - Escores Fatoriais, obtidos por meio do IHS- Del-Prette, nas fases pré e pós-intervençáo}

\begin{tabular}{|c|c|c|c|c|}
\hline \multirow{3}{*}{ PARTICIPANTES } & \multicolumn{4}{|c|}{ HABILIDADES SOCIAIS } \\
\hline & \multicolumn{2}{|c|}{ Enfrentamento com riscos (F1) } & \multicolumn{2}{|c|}{ Expressão de afeto positivo (F2) } \\
\hline & Pré & Pós & Pré & Pós \\
\hline P1 & 65 & 85 & 55 & 65 \\
\hline $\mathrm{P} 2$ & 10 & 65 & 45 & 75 \\
\hline P4 & 90 & 60 & 45 & 75 \\
\hline P5 & 1 & 1 & 30 & 3 \\
\hline P6 & 30 & 70 & 25 & 45 \\
\hline P7 & 30 & 80 & 15 & 15 \\
\hline P8 & 20 & 65 & 30 & 40 \\
\hline P9 & 20 & 60 & 25 & 80 \\
\hline P10 & 60 & 95 & 60 & 97 \\
\hline P11 & 30 & 10 & 25 & 20 \\
\hline P12 & 20 & 60 & 10 & 25 \\
\hline P13 & 15 & 15 & 20 & 45 \\
\hline
\end{tabular}

Nota: $\mathrm{F}$ = Fator; Escores: $<25 \%$ : necessidade de treino; Escores $>25 \%$ : bom repertório de Habilidades Sociais, porém abaixo da média; Escores $=50 \%$ : repertório mediano; Escores > a 50\%: bom repertório (acima da média) e Escores > 75\%: repertório bastante elaborado.

Com relação às HSE, os resultados foram organizados, considerando especialmente os registros cursivos das sessóes em que foi possível avaliar as habilidades em termos de frequência de emissão da resposta-alvo. De modo geral, com a intervenção, observouse que cerca de $85 \%$ dos participantes obtiveram mudança positiva. A habilidade que mais apresentou mudança positiva refere-se a "Solicitar informaçóes sobre o desempenho adequado do filho na escola".

Além disso, observou-se aumento na frequência dos seguintes comportamentos: a) descrição detalhada do comportamento esperado; b) variabilidade de situações utilizadas para ensinar comportamentos sociais às crianças (aproveitar acontecimentos cotidianos; elogio e feedback); c) emissão de consequências contingentes aos comportamentos adequados ou inadequados dos filhos (negociar regras); d) Estabelecimento e descrição de consequências de forma mais adequada (negociar regras, elogio e feedback, descrever comportamentos adequados e inadequados); e) Identificaçáo de situaçóes que tornam os comportamentos mais prováveis (mediar interaçóes; descrever comportamentos adequados e inadequados); f) Incentivar interaçóes com outras pessoas (antes da intervençáo, a frequência de emissáo dessa resposta era muito baixa, especialmente pela impulsividade das crianças, geralmente, relatada pela máe).

Adicionalmente, merece destaque a redução de frequência, após a intervenção, dos comportamentos de comparar o filho a outras crianças/pessoas e de emitir consequências punitivas (punição negativa) contingente aos comportamentos inadequados. Apesar de entender que esses comportamentos não compóem as HSE, a sua redução contribui para a melhoria da interação entre pais e filhos.

Por fim, considerando mais uma vez os registros cursivos das sessóes, cabe destacar que as sessóes destinadas à discussão dos aspectos gerais do TDAH e princípios da aprendizagem se fizeram importantes para esclarecimento de dúvidas e empoderamento dos pais quanto ao seu papel no processo de educaçáo dos filhos, uma vez que muitos pais desconheciam informaçóes relevantes sobre o transtorno, tais como: causas, efeitos para a vida da criança e da família, mecanismos de ação do medicamento (Ritalinaß) 
e a crença que muito pouco podiam fazer já que a criança havia "nascido" com esse transtorno.

Quanto a esse último, as sessóes de princípios de aprendizagem foram de suma relevância para se desmistificar tal crença, pois as discussóes reservadas a esse tema buscaram, baseadas no modelo de seleção por consequências proposto por Skinner (1981): a) elucidar que todo organismo é em si diferente e, por essa razão, procura-se desenvolver estratégias mais favoráveis a sua adaptação e b) viabilizar a percepção por parte dos pais acerca da relação contingente entre uma situação ambiental, sua ação e uma consequência que a segue, chamando atenção para a relação entre seu comportamento e de seus filhos e de seu papel na ampliação e manutenção de repertórios socialmente habilidosos nos mesmos, apesar de sua configuração. Assim, pode-se afirmar que os resultados positivos aqui discutidos estão diretamente relacionados à promoção de análise funcional durante as sessóes.

\section{Discussáo}

Os dados apresentados demonstraram que houve mudanças positivas nas habilidades sociais cotidianas e educativas dos pais após a intervenção. Da mesma forma, a maioria das crianças foram avaliadas positivamente pelos pais e professores.

Com relação às habilidades sociais das crianças, a avaliação de $85 \%$ dos pais apontou que houve benefícios com o programa sobre esses comportamentos e $92 \%$ deles relataram reduçáo nos comportamentos problemáticos em pelo menos um dos três fatores avaliados. Os ganhos no repertório de HS das crianças pode ter ocorrido devido a dois fatores: a) a realizaçáo das tarefas de casa pelos pais, que favorece a generalização para o ambiente natural, propicia condiçóes para o cliente aprender, gradualmente, a realizar a análise funcional de seu desempenho e fornecem indicaçóes, aos terapeutas, sobre as reaçôes dos significantes do cliente e as possíveis falhas em seu desempenho no ambiente natural, podendo corrigi-las no processo de intervenção (DEL PRETTE; DEL PRETTE, 2010); b) a importância atribuída pelos pais às HS avaliadas, pois se observou que $92 \%$ dos pais relataram valorizar os comportamentos englobados nas classes condizentes com os fatores avaliados. Essa valorização é uma das questôes mais importantes no ensino de habilidades sociais, pois quando são valorizadas, apresentam maior probabilidade de serem ensinadas ou mantidas pelos agentes significativos do ambiente da criança (ELLIOTT et al., 2008).

No que concerne aos problemas de comportamento, efeitos mais robustos foram observados para comportamentos internalizantes. Esses dados diferem da literatura (PFIFFNER; MCBURNETT, 1997), possivelmente, por ser uma classe de comportamento pouco percebido por pais e professores (RIBEIRO, 2013). No entanto, melhoras nessa classe podem sugerir o desenvolvimento de recursos para uma melhor adaptação que permitem à criança com TDAH lidar de forma mais efetiva com demandas emocionais (TEODORO; CARDOSO; PEREIRA, 2011).

Quanto ao desempenho acadêmico, avaliado pelos professores, observou-se que, com exceção de três participantes ( $\mathrm{P} 6, \mathrm{P} 7 \mathrm{e}$ P10), todos os demais apresentaram mudanças positivas. Cabe destacar que P10 também teve avaliaçáo positiva nas habilidades sociais, porém o escore não foi suficiente para alterá-lo de posição. Assim, os dados sobre desempenho acadêmico fornecem indicativos adicionais sobre a noção de habilidades 
sociais como facilitadores do desempenho acadêmico de crianças (MOLINA; DEL PRETTE, 2006; DiPERNA; ELLIOTT, 2002), visto que a intervenção priorizou apenas as habilidades sociais. Para Feitosa et al. (2011), resultados como esse se devem, provavelmente, ao fato dos processos de ensino-aprendizagem ocorrerem basicamente em um ambiente social e a qualidades dos relacionamentos interpessoais mantidos nesse contexto afetarem de forma positiva ou negativa o desempenho acadêmico.

$\mathrm{Na}$ autoavaliaçáo dos pais, observou-se que $67 \%$ dos pais obtiveram mudança positiva nas habilidades de enfrentamento com risco (fator 1). Esse dado é importante visto que famílias de crianças com TDAH vivenciam uma maior sobrecarga emocional se comparadas às famílias de crianças com desenvolvimento típico (BELLE et al, 2009; JOHNSTON; MASH, 2001). Portanto, os benefícios obtidos nesse fator indicam desenvolvimento de respostas assertivas e de controle de ansiedade em situaçóes como: lidar com críticas injustas, argumentar com profissionais como médicos e professores, discordar de outras pessoas, ou outras que envolvam caráter aversivo que esses pais vivenciam no seu dia a dia.

Já no Fator 2, "Habilidades de auto-afirmação na expressão de afeto positivo", 75\% da amostra apresentou mudança positiva. Entre as condutas referentes a esse fator estão as de elogiar familiares, expressar sentimento positivo, defender uma outra pessoa num grupo, dentre outras (BARTHOLOMEU; NUNES; MACHADO, 2008). Logo, os dados indicam que, após a intervenção, os pais aumentaram a frequência dessas respostas, especialmente no trato com seus filhos. A emissão desses comportamentos pode servir de modelos para o desenvolvimento de respostas dessa classe pelas crianças, contribuindo, assim, para o seu desenvolvimento (BOLSONI-SILVA; DEL PRETTE, 2003). Ainda nesse sentido, entende-se que a expressão do afeto positivo é um dos fatores protetores do desenvolvimento do jovem (CONTE, 1997).

Quanto às habilidades sociais educativas (HSE), observou-se que aproximadamente $85 \%$ dos participantes obtiveram mudanças positivas. Esse resultado, apesar de não tão robusto quanto se desejaria, pode ser visto como uma direçáo importante de intervençáo para pais de crianças com TDAH.

Dentre as habilidades sociais educativas, houve maior frequência, conforme relatos nas sessōes, daquela denominada "Solicitar informações sobre o desempenho adequado do filho na escola". Isso ocorreu, provavelmente, devido às contingências culturais que, em termos de escolarização, ainda priorizam os aspectos eminentemente acadêmicos. Por outro lado, ensinar pais a questionar sobre comportamentos adequados dos filhos na escola pode induzir a uma mudança na cultura escolar, em que as interaçóes entre pais e escola também possam ocorrer em função dos comportamentos considerados adequados e, principalmente, contribuir para estabelecer um contexto que valoriza as potencialidades dessas crianças (ROCHA, 2009).

Entretanto, propostas de atendimento, como essa apresentada, sofrem com a baixa adesão dos pais, como verificado no decorrer do projeto. A revisão de literatura feita por Fabiano et al. (2009) demonstrou que há certo consenso entre os estudos que os efeitos positivos obtidos em programas para pais são geralmente atenuados devido à frequente falta de adesão dos pais. O autor afirma que na literatura revisada foi observado que mais da metade das famílias que se disponibilizaram ao programa não compareceram ou desistiram do mesmo antes de finalizá-lo. A baixa taxa de adesão por parte dos pais se configura em uma problemática devido ao fato de que o TDAH, por se tratar de uma 
condição considerada crônica, requer envolvimento contínuo das famílias para o alcance de benefícios, de tal forma que a ausência dos pais demarca prejuízos no desenvolvimento pleno de seus filhos.

De forma geral, os efeitos sobre as habilidades dos pais corroboraram com os resultados apontados por estudos que abordam programas de treinamento comportamental para pais, sugerindo que os mesmos contribuem para o desenvolvimento de habilidades dos pais no manejo dos comportamentos de suas crianças, diminuem os sintomas de TDAH e amenizam os problemas de comportamento em casa (HUANG et al., 2003). Além disso, reafirma a importância da participação e da parceria da família, a fim de garantir o acesso, a permanência e o sucesso dessas crianças na escola.

\section{Consideraçóes Finais}

Diante do exposto, considera-se que os objetivos do programa foram alcançados, tanto no que concerne à melhoria da qualidade do relacionamento interpessoal entre pais e crianças com TDAH, através do treino de habilidades sociais e compartilhamento de informaçóes, quanto à promoção de habilidades sociais das crianças como efeito indireto de treino de habilidades sociais educativas realizado com os pais.

Apesar das vantagens aqui constatadas para a população alvo do programa, uma dificuldade encontrada no decorrer do projeto foi a baixa adesão dos pais, pois poucos aceitaram participar dele e menos ainda foram aqueles que o concluíram, como observado na descrição dos grupos. Por essa razão, esforços estão sendo mobilizados para desenvolver, aprimorar e efetivar duas alternativas concomitantes, visando maior adesáo dos pais ao programa apresentado: a) diminuição no número de sessóes, acompanhando os programas clássicos para pais que envolvem oito sessóes; b) a inclusão da criança em atendimentos paralelos, aumentando a motivação dos pais que, geralmente, requerem e depositam mais esperança de mudanças nos atendimentos que envolvem as crianças diretamente.

Adicionalmente, o programa poderá ser aplicado aos professores, visto que intervençóes com professores têm se mostrado efetivas (REIS; CAMARGO, 2008; VILA, 2005; da ROCHA; CARRARA, 2011, MOLINA, 2007) e de amplitude vasta, além de consistente no que concerne à otimização de práticas educativas positivas (LOPES, 2013).

Ainda que o número de pais participantes tenha sido pequeno e que o projeto tenha se restringido apenas a duas escolas, os resultados confirmam a necessidade e os efeitos positivos desse tipo de atendimento a pais de crianças com TDAH. Ao mesmo tempo, fornece indicativos importantes sobre os desafios desse tipo de intervenção.

Por fim, pode-se considerar que o projeto de extensão se constituiu em um espaço de aprendizagem para os acadêmicos, contribuindo para sua formação profissional, haja vista a oportunidade de unir teoria à prática, por meio de informação e de orientação de aspectos práticos aos participantes do grupo. Ao mesmo tempo, viabilizou à populaçãopara a qual o serviço foi destinado, momentos para trocas de experiência para sanar dúvidas, identificar e treinar estratégias que possibilitassem a melhoria da qualidade de vida, tanto de seus filhos, como dos próprios pais. 


\section{Referências}

APA-AMERICAN PSYCHIATRIC ASSOCIATION et al. Manual diagnóstico e estatístico de transtornos mentais (DSM IV). Washington: APA, 2002.

BARKLEY, R. A.Attention-deficit hyperactivity disorder: a handbook of diagnosis and treatment.New York: Guilford, 1998.

BARKLEY, R. A.; PFIFFNER, K. J. Rumo à escola com o pé direito: Administrando a educação de seu filho. In BARKLEY, R. A. (Org.), Transtorno de Déficit de Atenção/Hiperatividade (TDAH): Guia completo para pais, professores e profissionais da saúde. Tradução de ROIZMAN, L. S. Porto Alegre: Artmed, 2002.

BARTHOLOMEU, D.; NUNES, C. H. S. S.; MACHADO, A. A. Traços de personalidade e habilidades sociais em estudantes universitários. Psico-USF, v.12, n.1, jan/jun 2008, p.4250.

BRASIL. Política Nacional de Educação Especial na Perspectiva da Educação Inclusiva. Ministério da Educação. Brasília: SEESP, 2008.

BELLÉ, A. H. et al. Estresse e adaptação psicossocial em mães de crianças com transtorno de déficit de atenção/hiperatividade. Psicologia: Reflexão e Crítica, v. 22, n. 3, 2009, p. 317-325.

BOLSONI-SILVA, A. T.; DEL PRETTE, Z. A. P. Problemas de comportamento: Um panorama da área. Revista Brasileira de terapia comportamental e cognitiva, vol. V, n², 2003, p. 91-103.

CONDEMARÍN, M. et al. Transtorno do déficit de atenção e hiperatividade: estratégias para o diagnóstico e a intervenção psico-educativa. 1.ed. São Paulo: Ed. Planeta do Brasil, 2006.

CONTE, F. C. Promovendo a relação entre pais e filhos. In: DELLITI, M. (Org). Sobre Comportamento e Cognição. Santo André: Arbytes Editora, 1997, p. 165-173.

DEL PRETTE, Z. A. P.; DEL PRETTE, A. Psicologia das habilidades sociais na infância: teoria e prática. Petrópolis: Vozes, 2005.

DEL PRETTE, Z. A. P.; DEL PRETTE, A. Um sistema de categorias de habilidades sociais educativas.Paidéia, v.18, n.41, 2008, p. 517-530.

DEL PRETTE, A.; DEL PRETTE, Z.A.P. Psicologia das relações interpessoais: Vivências para o trabalho em grupo. 8. ed.Petrópolis: Vozes, 2010.

DIPERNA, J. C.; ELLIOTT, S. N. Promoting academic enablers to improve student achievement: an introduction to the mini-series. School Psychology Review, v. 31, n. 3, 2002, p. 293-297. 
DUPAUL, G.J.; WHITE, G.P. ADHD: Behavioral, educational and medication interventions. The Education Digest, vol.71, n.7, 2006, p.57-60.

ELLIOTT, S. N.; GRESHAM, F. M.; FRANK, J. L.; BEDDOW, P. A., III. Intervention validity of social behavior rating scales: features of assessments that link results to treatment plans. Assessment for Effective Intervention, vol. 34, n. 1, 2008. p. 15-24.

FABIANO G.A., et al. A comparison of behavioral parent training programs for fathers of children with attention-deficit/hyperactivity disorder.BehaviorTherapy, n. 40, v. 2, 2009, p.190-204.

FEITOSA, F. B., DEL PRETTE, Z. A. P., DEL PRETTE, A.; LOUREIRO, S. R. Explorando relações entre o comportamento social e o desempenho acadêmico de crianças. Estudos e Pesquisas em Psicologia, vol.11, n.2, 2011, p.442-455.

FREITAS, L. C.; DEL PRETTE, Z. A. P. Habilidades sociais de crianças com diferentes necessidades educacionais especiais: Avaliação e implicações para intervenção. Avances en Psicología Latinoamericana, v. 31, n. 2, 2013, p.344-362.

GRESHAM, F. M.; ELLIOT, S. Social Skills Rating System. Circle Pines, MN: American Guidance Service, 1990.

HUANG, H. L.; CHAO, C. C.; TU, C. C.; YANG, P. C. Behavioral parent training for taiwanese parents of children with attention-deficit/hyperactivity disorder. Psychiatry and Clinical Neurosciences, v. 57, 2003, p. 275-281.

JOHNSTON, C.; MASH, E. J. Families of children with attention-deficit/hyperactivity disorder: review and recommendations for future research. Clinical Child and Family Psychology Review. v.4, n.3., 2001, p.183-207.

LOPES. D. C. Programa universal de habilidades sociais aplicado pelo professor: impacto sobre comportamentos sociais e acadêmicos. 2013. 245f. Tese (Doutoramento em Psicologia). Universidade Federal de São Carlos, São Carlos, 2013.

MOLINA, R. C. M.; DEL PRETTE, Z. A. P. Funcionalidade da relação entre habilidades sociais e dificuldades de aprendizagem. Psico-USF, n. 11, v. 1, 2006, p. 53-63.

MOLINA, R. C. M. Avaliação de programas de treinamento de professores para promover habilidades sociais de crianças com dificuldades de aprendizagem. 2007. 166 f. Tese (Doutoramento em Educação Especial). Universidade Federal de São Carlos, São Carlos, 2007.

MURTA, S. G. Aproximando ciência e comunidade: Difusão de programas de hs baseados em evidências. In: DEL PRETTE, Z. A. P; DEL PRETTE, A. (Eds.), Habilidades sociais: intervenções efetivas em grupo. São Paulo: Casa do Psicólogo, 2011, p.83-111.

PFIFFNER L.J, MCBURNETT K. Social skills training with parent generalization: treatment effects for children with attention deficit disorder. Journal of Consulting and Clinical Psychology, v. 65, n.5, 1997, p.749-757. 
REIS, M. G. F.; CAMARGO, D. M. P. de. Práticas escolares e desempenho acadêmico de alunos com TDAH. Revista Semestral da Associação Brasileira de Psicologia Escolar e Educacional (ABRAPEE), v. 12, n.1, 2008, p.89-100.

RIBEIRO, A. F. Comparação de padrões comportamentais referidos por múltiplos informantes e desempenho neuropsicológico na caracterização de sinais de desatenção e hiperatividade em adolescentes. 2014. 95f. Dissertação (Mestrado em distúrbios do desenvolvimento). Universidade Presbiteriana Mackenzie, São Paulo, 2013.

ROCHA, J. F. da.;CARRARA, K. Formação ética para a cidadania: reorganizando contingências na interação professor-aluno. Psicologia escolar e educacional, v.15, n.2, 2011, p. 221230.

ROCHA, M. M. Programa de habilidades sociais educativas com pais: efeitos sobre o desempenho social e acadêmico de filhos com TDAH. 2009. 235f. Tese (Doutoramento em Educação Especial). Universidade Federal de São Carlos, São Carlos, 2009.

ROCHA, M. M.; DEL PRETTE, Z. A. P.; DEL PRETTE, A. Avaliação de um Programa de Habilidades Sociais Educativas para mães de crianças com TDAH. Acta Comportamentalia, v.21, n.3, 2013, p.359-375.

ROCHA, M. M.; DEL PRETTE, Z. A. P. Habilidades sociais educativas para mães de crianças com TDAH e a inclusão escolar. PsicologiaArgumento, v.28, n.60, 2010, p.31-41. 
ROESER, R. W.; ECCLES, J. S. Schooling and mental health. In.: SAMEROFF, A. J.; LEWIS, M.; MILLER, S. M. (Orgs.) Handbook of developmental psychopathology. Nova York: Kluwer/Plenum, 2000, p.135-156.

ROHDE, L. A. et al. ADHD in a school sample of Brazilian adolescents: a study of prevalence, comorbid conditions, and impairments.Journal of the American Academy of Child and Adolescent Psychiatry, v. 38, n.6, p. 716-723, 1999.

ROHDE, L. A. et. al. Transtorno de déficit de atenção/hiperatividade na infância e na adolescência: considerações clínicas e terapêuticas.Revista psiquiatria clínica, v.31, n.3, p. 124-131, 2004.

SKINNER, B. F. Selection by consequences. Science, vol.213, n.4507, p.501-504, jul.1981.

TEODORO, M. L. M.; CARDOSO, B. M.; PEREIRA, T. F. P. As relações familiares e os problemas emocionais e de comportamento em adolescentes. In: WAGNER, A., et al. Desafios psicossociais da família contemporânea: pesquisa e reflexões. Porto Alegre, Artmed, 2011, p. 140-149.

VILA, E. M. Treinamento de habilidades sociais em grupo com professores de crianças com dificuldades de aprendizagem: uma análise sobre procedimentos e efeitos da intervenção. 2005. 128p. Dissertação (Mestrado em Educação Especial). Universidade Federal de São Carlos, São Carlos, 2005. 